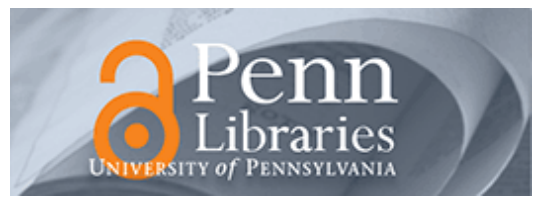

University of Pennsylvania

ScholarlyCommons

Accounting Papers

Wharton Faculty Research

$9-4-2008$

\title{
Optimal Contracting With Endogenous Social Norms
}

\author{
Paul E. Fischer \\ University of Pennsylvania
}

Steven Huddart

Follow this and additional works at: https://repository.upenn.edu/accounting_papers

Part of the Accounting Commons, and the Economics Commons

Recommended Citation

Fischer, P. E., \& Huddart, S. (2008). Optimal Contracting With Endogenous Social Norms. American

Economic Review, 98 (4), 1459-1475. http://dx.doi.org/10.1257/aer.98.4.1459

This paper is posted at ScholarlyCommons. https://repository.upenn.edu/accounting_papers/25

For more information, please contact repository@pobox.upenn.edu. 


\title{
Optimal Contracting With Endogenous Social Norms
}

\author{
Abstract \\ Research in sociology and ethics suggests that individuals adhere to social norms of behavior \\ established by their peers. Within an agency framework, we model endogenous social norms by \\ assuming that each agent's cost of implementing an action depends on the social norm for that action, \\ defined to be the average level of that action chosen by the agent's peer group. We show how \\ endogenous social norms alter the effectiveness of monetary incentives, determine whether it is optimal \\ to group agents in a single or two separate organizations, and may give rise to a costly adverse selection \\ problem when agents' sensitivities to social norms are unobservable. \\ Disciplines \\ Accounting | Economics | Social and Behavioral Sciences
}




\title{
Optimal Contracting with Endogenous Social Norms
}

\author{
By Paul Fischer and Steven Huddart*
}

\begin{abstract}
Research in sociology and ethics suggests that individuals adhere to social norms of behavior established by their peers. Within an agency framework, we model endogenous social norms by assuming that each agent's cost of implementing an action depends on the social norm for that action, defined to be the average level of that action chosen by the agent's peer group. We show how endogenous social norms alter the effectiveness of monetary incentives, determine whether it is optimal to group agents in a single or two separate organizations, and may give rise to a costly adverse selection problem when agents' sensitivities to social norms are unobservable. (JEL D23, D82, D86, Z13)
\end{abstract}

Research in social psychology suggests that social norms arise and influence individual behavior because individuals have innate preferences to conform to the behavior of their peers. ${ }^{1}$ When one's peers are other members of the same organization, such as a firm or a profession, this research suggests that the behavior of individuals in an organization determines the social norms for the organization which, in turn, influence individual behavior. It follows from this interplay between individual behavior and social norms that social norms are endogenous and ultimately determined by exogenous design choices, such as the organization's incentive contracts, boundaries, and membership.

To assess how social norms and organizational design interact, we analyze a principal-agent model in which a principal contracts with a continuum of agents. In our main model, each agent influences the performance measure that determines his compensation through two action choices, called the desirable action choice and the undesirable action choice. The desirable action yields some benefit to the principal, while the undesirable action imposes a cost on the principal. For example, the desirable action may represent the agent's productive effort and the undesirable action may represent detrimental earnings management activities undertaken by the agent. ${ }^{2} \mathrm{We}$

* Fischer: Smeal College of Business, Pennsylvania State University, University Park, PA 16802-3603 (e-mail: pfischer@psu.edu); Huddart: Smeal College of Business, Pennsylvania State University, University Park, PA 168023603 (e-mail: huddart@psu.edu). We thank Kalyan Chatterjee, Michel Clement, Shane Dikolli, Mark Dirsmith, Don Hambrick, Michael Kirschenheiter, Richard Sansing, Steven Schwartz, Shiva Sivaramakrishnan, Linda Treviño, Amir Ziv, two anonymous reviewers, and seminar participants at the 2004 meetings of the American Accounting Association, Carnegie Mellon University, Columbia University, Duke University, the Ohio State University, SUNY-Binghamton, the University of Alberta, and the University of Houston for helpful discussions. We gratefully acknowledge financial support from the Smeal Competitive Research Fund.

${ }^{1}$ In the social psychology literature, Lawrence Kohlberg (1984) develops a framework of moral development in which individuals prefer to conform to norms established by their peers. Subsequent studies have developed psychometric instruments that measure this preference and conclude that the majority of individuals within professional organizations of adults prefer to conform, although the strength of this preference varies from individual to individual. A related construct in psychology is the locus of control developed by Julian B. Rotter (1966).

${ }^{2}$ An extensive accounting literature considers accounting (e.g., bookkeeping) manipulation. See, for example, Ronald A. Dye (1988), Paul E. Fischer and Robert E. Verrecchia (2000), or the survey of empirical evidence discussed in Thomas D. Fields, Thomas Z. Lys, and Linda Vincent (2001). In addition, there is extensive evidence that managers make real decisions (e.g., channel stuffing or foregoing research and development expenditures) to manipulate nearterm performance measures. See, for example, Jeremy C. Stein (1989) or David Hirshleifer (1993) or, for some empirical evidence, Paul E. Oyer (1998) and Merle Erickson, Michelle Hanlon, and Edward L. Maydew (2004). 
assume a separate norm for each action, where the norm for an action affects the cost of that action to every agent (e.g., by inducing feelings of satisfaction or guilt) and thereby influences every agent's action choice. To reflect behaviors described in the sociology literature, the social norm ultimately causes each agent to choose a higher action level when his peers choose a higher action level. ${ }^{3}$

We incorporate both desirable and undesirable actions, and a corresponding norm for each, in our analysis because both types of actions and norms appear to be economically relevant. In the business realm, for example, shortcomings in corporate culture have been attributed not simply to the demise of social norms encouraging desirable actions, such as diligent effort, but also to the erosion of social norms that thwart undesirable actions, especially the manipulation of financial reports. ${ }^{4}$ Furthermore, outside the business realm, recent empirical studies provide evidence that norms for both types of actions affect individual choices. For example, Raymond Fisman and Edward Miguel (2006) study the differing propensities of Nigerian and Norwegian diplomats posted to New York City to accumulate unpaid parking tickets-an undesirable action-and conclude that social norms related to corruption are significant and persistent because diplomats behave like others in their home countries. As another example, E. Han Kim, Adair Morse, and Luigi Zingales (2006) report that academics' research productivity—a desirable action—is influenced by the cultural norm of the department that houses them.

Our analysis suggests that norms for desirable and undesirable actions have different implications for organization design. For example, the presence of a norm for desirable action multiplies the benefits of financial incentives, while the presence of a norm for undesirable action reduces the benefits. In addition, agents' relative sensitivities to each type of norm determines whether it is beneficial to split an organization apart to foster different norms in each part. As a final example, unobservable individual differences in sensitivity to social norms create a costly adverse selection problem when the differences pertain to social norms for undesirable actions, but not when the differences pertain to social norms for desirable actions.

Other papers have considered how nonmonetary incentives, such as social norms, have consequences for the returns to financial incentives. In a setting with a single agent, Roland Bénabou and Jean Tirole (2003) formalize the notion that monetary incentives can crowd out incentives provided by intrinsic factors. Relatedly, experimental and field study work in a nonbusiness setting by Uri Gneezy and Aldo Rustichini (2000a, b) supports the notion that intrinsic factors can undermine the effectiveness of financial incentives. They find that introducing financial incentives in a nonbusiness setting can lead to less of a desirable action (correct answers to test questions) and more of an undesirable action (the tardy collection of children from a day care center), respectively. Their evidence of important interactions between extrinsic (i.e., monetary) and intrinsic (e.g., a social norm) incentives suggests that norms, in addition to standard compensation mechanisms, merit study.

In an agency study of team production incorporating a norm, Steffen Huck, Dorothea Kübler, and Jörgen Weibull (2006) show that strong monetary incentives tied to aggregate team production can rule out Pareto-preferred equilibria that are attainable if incentives are weak and norms are strong. In another agency study, Dirk Sliwka (2007) shows that firms may forego highpowered incentive contracts because they attract agents who respond solely to the incentives

\footnotetext{
${ }^{3}$ Models of reciprocation have interdependent preferences, which is a feature analogous to our social norm. Ernst Fehr and Armin Falk (2002) distinguish between two human social desires that interact with economic incentives: the desire for social approval and the desire to reciprocate - see, e.g., Gary Bolton and Axel Ockenfels (2000) and Gary Charness and Matthew Rabin (2002), who examine how notions of equity and fairness influence behavior. These models do not address social norms with respect to unobservable acts, which is the focus of our study.

${ }^{4}$ See, for example, the comments of Arthur Levitt (1998), who is a former Securities and Exchange Commission Chairman.
} 
which, in turn, undermines the behavior of agents employed by that firm who conform to the behavior of others. These agency studies do not consider how norms determine organizational boundaries or membership.

Because we use a two-action framework, this study relates to the multitask agency literature initiated by Bengt Holmström and Paul Milgrom (1991). The model considered here differs from the models in that literature because (a) social norms induce interdependence in the agents' utility functions and (b) the undesirable action is detrimental to the principal even though it favorably influences the performance measure. Because of this latter feature, our study relates to work by Canice Prendergast (1999), who analyzes how counterproductive influence activities can improve subjective evaluation measures.

Finally, some tax and welfare policy research also considers the role of norms. The tax compliance studies of Jon S. Davis, Gary Hecht, and Jon D. Perkins (2003) and Joel Slemrod (2004) suggest that social norms are important to tax compliance. In a related vein, N. Soren Blomquist (1993) and Assar Lindbeck, Sten Nyberg, and Weibull (1999) consider the effects of tax and welfare policy, respectively, on labor supply when norms influence behavior.

The paper proceeds as follows. Section I presents a single (desirable) action model with a single social norm, which introduces and motivates the intuition for the two-action two-norm model presented in Section II. Section III characterizes the cost of implementing a particular set of desirable actions, which is necessary for the analyses in Sections IV and V. Section IV considers how changing organization boundaries, which alters the social norms faced by agents, affects the cost of implementing a set of actions. Section V identifies the behavioral traits that are preferred within particular organizations and considers whether contracts exist that attract only the agents with the desired traits. Section VI concludes.

\section{Single Action Model}

Consider an agency model in which a principal employs a continuum of risk-neutral agents, each of whom must undertake a single task. The agents are indexed by a compact set $\mathcal{I}$ having strictly positive measure. The agents have a common reservation level of expected utility, $v$. After contracts are signed, each agent $i \in \mathcal{I}$ chooses a level of some desirable action, $a_{i} \geq 0$, which the principal cannot observe.

Contracts are linear, so that agent $i$ 's compensation is $w_{i}+b_{i} r_{i}$, where $w_{i} \in \mathbb{R}$ and $b_{i}>0$ are the contract parameters, and $r_{i}$ is a stochastic report that determines agent $i$ 's compensation. The mean of $r_{i}$ is $h\left(a_{i}\right)$, where $h^{\prime}>0, h^{\prime \prime} \leq 0, h^{\prime}(x)$ approaches infinity as $x$ approaches 0 ; and $h^{\prime}(x)$ approaches 0 as $x$ approaches infinity. ${ }^{5}$ Attention is restricted to linear contracts because these contracts make intuitive the interplay between the power of incentives, represented by the $b_{i}$ 's, and social norms. Furthermore, linear contracts are efficient in this setting. ${ }^{6}$

Given contract $\left\{w_{i}, b_{i}\right\}$, agent $i$ chooses $a_{i}$ to maximize

$$
z\left(a_{i}\right) \equiv w_{i}+b_{i} h\left(a_{i}\right)-f\left(a_{i}-N_{a_{i}}\right)
$$

where $f$ is a cost function with continuous derivatives defined over the real line, and $f^{\prime}>0$ and $f^{\prime \prime}>0$. Finally, agent $i$ 's cost, $f\left(a_{i}-N_{a_{i}}\right)$, is influenced by a norm parameter, $N_{a_{i}}$, which affects

\footnotetext{
${ }^{5}$ Restricting attention to cases where $b_{i}$ is strictly positive, which is necessary and sufficient for agent $i$ to choose an interior level of action, simplifies the proofs without affecting the formal results.

${ }^{6}$ If the density function for $r_{i}$ as a function of $a_{i}$ can be written in the form $g\left(r_{i}, a_{i}\right)$, then restricting attention to linear contracts is without loss of generality because linear contracts are as efficient as any other contract that induces any interior set of desirable actions by the agents of an organization.
} 
$i$ 's total and marginal costs of $a_{i}$. Formally, a higher value for the norm reduces the marginal cost of $a_{i}$ because $d^{2} f\left(a_{i}-N_{a_{i}}\right) / d a_{i} d N_{a_{i}}=-f^{\prime \prime}<0$.

Including the norm $N_{a_{i}}$ in the cost function for the action captures the idea that, in addition to any physical or cognitive cost, action choices have an emotional cost that is determined in part by norms of behavior. For example, an individual may have a personal ethic that supports hard work, which we term a personal norm. In addition, an individual may be part of an organization with a cultural ethic that supports hard work with feelings of satisfaction, which we term a social norm. A higher norm of either type inclines an individual to work harder for a given level of financial incentives. Accordingly, we assume that individual $i$ 's norm, $N_{a_{i}}$, is a weighted average of agent $i$ 's personal norm, $A_{i} \in \mathbb{R}$, and a common social norm for the action, $S_{a}$, which is the per-capita average level of the actions of other agents in $i$ 's organization. Formally, the norm for agent $i$ in an organization $\mathcal{I}$ is

$$
\begin{gathered}
N_{a_{i}} \equiv\left(1-\alpha_{i}\right) A_{i}+\alpha_{i} S_{a}, \text { where } \\
S_{a} \equiv \frac{\int_{\mathcal{I}} a_{i} d_{i}}{\int_{\mathcal{I}} d_{i}} .
\end{gathered}
$$

Parameter $\alpha_{i} \in[0, \bar{\alpha}]$, where $0 \leq \bar{\alpha}<1$, represents the extent to which agent $i$ is influenced by the behavior of others in his organization through the social norm, and $\alpha_{i}>0$ implies that $i$ chooses a higher $a_{i}$ in response to an increase in the average action of his peers.

The payoff that the principal derives from a given supply of the action is unspecified because our primary focus is on the minimum cost of implementing the desirable action. Nonetheless, the principal cares about the agents' actions because they generate some valuable noncontractible payoff. The principal uses the report only as a source of information (i.e., the report has no intrinsic value). Further, analogous to models of atomistic agents where each agent is a price taker, observe that agents are "norm takers" because each agent's action choice has no measurable effect on the social norm, $S_{a}$. Finally, each agent correctly anticipates the social norm, $S_{a}$, that actually prevails in his organization, which is analogous to a rational expectations assumption. ${ }^{7}$

\section{A. Post-Contracting Equilibrium}

A post-contracting equilibrium for contract parameters $\left\{w_{i}, b_{i}\right\}_{i \in \mathcal{I}}$ is a set of actions, $\left\{a_{i}\right\}_{i \in \mathcal{I}}$, such that for each $i, a_{i}$ maximizes objective (1) given $\left\{w_{i}, b_{i}\right\}$ and $S_{a}$, and $S_{a}$ satisfies equation (3) given $\left\{a_{i}\right\}_{i \in \mathcal{I}}$. To prove the existence and uniqueness of a post-contracting equilibrium, we first derive each agent's optimal action choice given the agent's contract and the social norm. The mathematical properties of agent $i$ 's objective imply that the first-order condition completely characterizes $i$ 's action choice:

$$
z^{\prime}\left(a_{i}\right)=b_{i} h^{\prime}\left(a_{i}\right)-f^{\prime}\left(a_{i}-\left(1-\alpha_{i}\right) A_{i}-\alpha_{i} S_{a}\right)=0 .
$$

By applying the implicit function rule to this first-order condition, $a_{i}$ can be written as an implicit function of $S_{a}, a_{i}\left(S_{a}\right)$, where:

$$
\frac{\partial a_{i}\left(S_{a}\right)}{\partial S_{a}}=\frac{\left.\alpha_{i} f^{\prime \prime}\left(a_{i}-\left(1-\alpha_{i}\right) A_{i}-a_{i} S_{a}\right)\right)}{-b_{i} h^{\prime \prime}\left(a_{i}\right)+f^{\prime \prime}\left(a_{i}-\left(1-\alpha_{i}\right) A_{i}-a_{i} S_{a}\right)} \in\left[0, \alpha_{i}\right) .
$$

\footnotetext{
${ }^{7}$ Note that norms influence behavior by altering each agent's cost of the desirable action. Norms also may influence agent behavior in ways we do not model. For example, an agent may bear a cost when affiliated with an organization with low social norms because he is treated poorly by his colleagues. We thank a referee for suggesting this point.
} 
To complete the proof, we establish that there is a unique $S_{a}$ such that

$$
S_{a}-\frac{\int_{\mathcal{I}} a_{i}\left(S_{a}\right) d_{i}}{\int_{\mathcal{I}} d_{i}}=0
$$

The left-hand side of equation (6) evaluated at $S_{a}=0$ is strictly negative and increases monotonically and continuously in $S_{a}$ at a rate greater than $1-\bar{\alpha}>0$. It follows that there is a unique value of $S_{a}$, which is positive and finite, that satisfies equation (6). Hence, we have the following lemma.

LEMMA 1: For any set of contracts, $\left\{w_{i}, b_{i}\right\}_{i \in \mathcal{I}}$ for organization $\mathcal{I}$, there exists a unique postcontracting equilibrium, $\left\{a_{i}\right\}_{i \in \mathcal{I}}$.

\section{B. Multiplier Effects}

To gain some insight into the role played by the social norm, we present comparative statics in a setting where all agents have identical contracts and preferences so that $b_{i}=b, A_{i}=A$, and $\alpha_{i}=\alpha$ for all $i \in \mathcal{I}$. As a result, $a_{i}=a$ for $i \in \mathcal{I}$. Analysis of the first-order condition (4) leads to

$$
\frac{d a}{d y}=\frac{\partial z^{\prime}(a) / \partial y}{-b h^{\prime \prime}(a)+(1-\alpha) f^{\prime \prime}\left(a-N_{a}\right)}+\frac{d S_{a}}{d y} \frac{\alpha f^{\prime \prime}\left(a-N_{a}\right)}{-b h^{\prime \prime}(a)+f^{\prime \prime}\left(a-N_{a}\right)},
$$

where $y$ is $b, A$, or $\alpha$ and $d S_{a} / d y$ is the change in the post contracting equilibrium social norm implied by (6). The first term on the right-hand side of equation (7), which is proportional to $\partial z^{\prime}(a) / \partial y$, is the direct effect of the parameter change on agents' actions. The second term, which is proportional to $d S_{a} / d y$, captures the impact of the change in the norm attributable to the change in the exogenous parameter. Furthermore, because $a=S_{a}$, this indirect effect is of the same sign as the direct effect. Assuming agents are sensitive to the social norm (i.e., $\alpha>0$ ), the indirect effect multiplies the direct effect. For example, if the direct effect causes each agent to work a bit harder, the additional hard work favorably affects the social norm which, in turn, causes each agent to work harder still. Formally, we have the following corollary.

COROLLARY 1: Assume identical agents with identical contracts. The agents' actions are increasing in the power of incentives, da/db $>0$, and increasing in their personal norm, da/dA $>0$. Whether the agents' actions are increasing or decreasing in the agents' sensitivities to the social norm depends on whether the social norm is higher or lower than the personal norm: $d a / d \alpha>0$ if $S_{a}>A$, and $d a / d \alpha<0$ if $S_{a}<A$.

Consider, first, changes in the incentive parameter $b$. The direct effect is positive-greater incentives induce more of the desirable action-and this effect is reinforced by the concomitant increase in the social norm. An increase in the agents' respective personal norms, $A$, also increases the desirable action. Again, because the increased personal norm translates into more desirable action, the social norm also increases, which induces yet higher effort. Finally, consider changes in the sensitivity to the social norm. If the social norm, $S_{a}$, is higher (lower) than the personal norm for each agent, $A$, an increase in agents' sensitivity to the social norm increases (decreases) the total norm, $N_{a}$, which provides a direct incentive to take a higher action, $a$. This direct effect is multiplied because the social norm also increases (decreases), which induces even more (less) desirable action. In summary, in the single-action setting, the social norm multiplies the effect on $a$ of any change in the exogenous parameters. 


\section{Desirable and Undesirable Action Choices with Two Norms}

Norms influence desirable actions, but they may also influence undesirable actions. For example, as discussed in the introduction, employees can engage in costly earnings management activities that improve reported performance but ultimately reduce firm value. To introduce norms that influence undesirable actions, we extend the base model to include a second action choice with its own norm. In the main model, each agent $i$ chooses two unobservable actions that affect the principal's welfare, a desirable action, $a_{i} \geq 0$, and an undesirable action, $u_{i} \geq 0$. The undesirable action, $u_{i}$, imposes a cost on the principal of $k_{i} u_{i}$ where $k_{i}>0$. Agent $i$ 's compensation is again restricted to be linear in a report, $r_{i}$; however, the mean of $r_{i}$ is now $h\left(a_{i}+u_{i}\right)$. As a consequence, the report does not allow the principal to distinguish $a_{i}$ from $u_{i}$. In addition, the agent's objective includes a cost associated with the undesirable action:

$$
z\left(a_{i}, u_{i}\right) \equiv w_{i}+b_{i} h\left(a_{i}+u_{i}\right)-f\left(a_{i}-N_{a_{i}}\right)-f\left(u_{i}+N_{u_{i}}\right) .
$$

Consistent with the notion that a higher level of the norm for the undesirable action should discourage the agent from taking that action, a higher value for the norm increases the marginal cost of $u_{i}$ (i.e., $\left.\partial^{2} f\left(u_{i}+N_{u_{i}}\right) / \partial u_{i} \partial N_{u_{i}}=f^{\prime \prime}>0\right)$.

The norm associated with the undesirable action is defined in a manner analogous to the norm for the desirable action:

$$
\begin{gathered}
N_{u_{i}} \equiv\left(1-\mu_{i}\right) U_{i}+\mu_{i} S_{u}, \text { where } \\
S_{u} \equiv-\frac{\int_{\mathcal{I}} u_{i} d i}{\int_{\mathcal{I}} d i}
\end{gathered}
$$

is the social norm for the undesirable action, $U_{i}$ is agent $i$ 's personal norm for the undesirable action, and $\mu_{i} \in[0, \bar{\mu}]$, where $0 \leq \bar{\mu}<1$, captures the extent to which agent $i$ is influenced by the undesirable behavior of others in the organization. In contrast to the desirable action social norm specification in (3), $S_{u}$ is defined so that the undesirable action norm for an agent is reduced when other agents engage in more of that action. This assumption, coupled with the assumption that a higher norm for undesirable action increases an agent's personal cost of that action, implies that an agent engages in more of the undesirable action when others in the organization engage in more of that action.

\section{A. Post-Contracting Equilibrium}

A post-contracting equilibrium for an organization of agents $\mathcal{I}$, who have contracts $\left\{w_{i}, b_{i}\right\}_{i \in \mathcal{I}}$, is defined as a set of actions, $\left\{a_{i}, u_{i}\right\}_{i \in \mathcal{I}}$, such that: (a) each agent's action choices maximize objective (8) given $\left\{w_{i}, b_{i}\right\}_{i \in \mathcal{I}}$; and (b) $S_{a}$ and $S_{u}$ satisfy equations (3) and (10) given $\left\{a_{i}, u_{i}\right\}_{i \in \mathcal{I}}$. As in the single-action model, the proof that there exists a unique post-contracting equilibrium begins by characterizing each agent's action choices as a function of the contract parameters and the social norms. The proof is completed by demonstrating that there exists a unique pair of social norms, $S_{a}$ and $S_{u}$, that satisfy (3) and (10). This and all subsequent proofs are in a Web Appendix (available at http://www.aeaweb.og/articles.php?doi=10.1257/aer.98.4.1459).

LEMMA 2: For any set of contracts, $\left\{w_{i}, b_{i}\right\}_{i \in \mathcal{I}}$ for organization $\mathcal{I}$, there exists a unique postcontracting equilibrium, $\left\{a_{i}, u_{i}\right\}_{i \in \mathcal{I}}$. If all agent choices are interior, then $a_{i}-N_{a_{i}}=u_{i}+N_{u_{i}}$ for all $i$.

The observation that $a_{i}-N_{a_{i}}=u_{i}+N_{u_{i}}$ when the agents' choices are interior implies that the action mix selected by agent $i$ shifts toward the desirable action as either his norm for the 
desirable action, $N_{a_{i}}$, increases or his norm for the undesirable action, $N_{u_{i}}$, increases. A higher norm for the desirable action reduces the marginal cost of that action to the agent. A higher norm for the undesirable action increases the marginal cost of that action, which induces the agent to supply more of the desirable action.

\section{B. Multiplier Effects}

In the single action setting, we demonstrated that the social norm for the desirable action multiplies the impact of changes in exogenous parameters on the desirable action choice. With two actions and a social norm for each, there are two multiplier effects, which can have offsetting effects on an agent's desirable action choice. To illustrate, we again employ a setting with identical contracts and agents: $b_{i}=b, A_{i}=A, U_{i}=U, \alpha_{i}=\alpha$, and $\mu_{i}=\mu$ for $i \in \mathcal{I}$. As a result, $a_{i}=$ $a$ and $u_{i}=u$ for $i \in \mathcal{I}$. Throughout, interior choices for both actions are assumed.

Consider the impact of an increase in the power of incentives, $b$. Holding constant the social norms, the direct effect of the increase in $b$ on the desirable and undesirable action choice leads to an increase in both actions. The increase in the desirable action choice causes an increase in the desirable action social norm, which yields the same multiplier effect as in the single action setting by making the desirable action less costly to each agent. The increase in the undesirable action choice causes a decrease in the undesirable action social norm, which makes the undesirable action less costly as well. If the two multipliers are unequal, the action mix shifts toward the action choice with the larger multiplier. Hence, if the multiplier on the undesirable action is larger, which occurs when $\mu$ is large, the impact of the change in $b$ on the desirable action is mitigated by the social norm for the undesirable action. It turns out that this effect is never large enough to dominate the direct effect, although the effect of an increase in $b$ on the desirable action approaches zero as the agents' sensitivity to the social norm for the undesirable action, $\mu$, approaches its upper bound, one.

When the personal norm for either the desirable or the undesirable action increases, the direct effect of the change causes the action mix to shift toward the desirable action. The change in the mix causes both social norms to increase, implying that each social norm creates a positive multiplier effect on the desirable action choices. If the social norm is higher than the personal norm (e.g., $S_{a}>A$ or $S_{u}>U$ ), then an increase in the sensitivity to either social norm causes the desirable action to increase. If the social norm is lower than the personal norm, then an increase in the sensitivity to either social norm causes the undesirable action to decrease. The following corollary summarizes these observations.

COROLLARY 2: Assume identical agents with identical contracts in the setting where the agents choose desirable and undesirable actions, and these actions are interior. The desirable and undesirable action choices for each agent are increasing in the power of incentives: da/db $>0$ and $d u / d b>0$. The desirable action choice is increasing and the undesirable action choice is decreasing in either personal norm: da/dA $>0$, da/dU $>0, d u / d A<0$, and $d u / d U<0$. Whether the desirable and undesirable actions are increasing or decreasing in the agents' sensitivities to the social norms depends on whether the social norm is higher or lower than the personal norm: (i) $d a / d \alpha>0$ and $d u / d \alpha<0$ if $S_{a}>A$, (ii) da/d $\alpha<0$ and $d u / d \alpha>0$ if $S_{a}<A$, (iii) $d a / d \mu>0$ and $d u / d \mu<0$ if $S_{u}>U$, and (iv) da/d $\mu<0$ and $d u / d \mu>0$ if $S_{u}<U$.

\section{Per-Capita Implementation Costs}

The post-contracting equilibrium allows us to determine the minimum cost to implement a specific set of desirable actions. The cost functions prove useful in analyzing how organizations 
can be structured to exploit endogenous social norms and how agents with differing behavioral traits (e.g., one's sensitivity to a social norm) can be allocated to organizations so as to minimize implementation costs. We develop the case of the desirable and undesirable actions. The results in the single-action setting are easily inferred from the more general setting.

An optimal contract set for implementing $\left\{a_{i}\right\}_{i \in \mathcal{I}}$ is a $\left\{w_{i}, b_{i}\right\}_{i \in \mathcal{I}}$ that minimizes the sum of the per-capita expected compensation and undesirable action costs,

$$
\frac{\int_{\mathcal{I}} w_{i}+b_{i} h\left(a_{i}+u_{i}\right)+k_{i} u_{i} d i}{\int_{\mathcal{I}} d i},
$$

subject to each agent attaining his reservation level of expected utility, $z\left(a_{i}, u_{i}\right) \geq v ; a_{i}$ and $u_{i}$ maximize $z\left(a_{i}, u_{i}\right)$ for each $i$; and, the endogenous social norms satisfy conditions (3) and (10). The reservation constraint for each agent $i$ is always binding, so the principal's objective can be rewritten as a function of the desirable actions, $\left\{a_{i}\right\}_{i \in \mathcal{I}}$, and the induced set of undesirable actions, $\left\{u_{i}\right\}_{i \in \mathcal{I}}$ :

$$
\frac{\int_{\mathcal{I}}\left[v+f\left(a_{i}-N_{a_{i}}\right)+f\left(u_{i}+N_{u_{i}}\right)+k_{i} u_{i}\right] d i}{\int_{\mathcal{I}} d i} .
$$

The restated objective function (11) identifies the components of the cost to the principal of inducing a given level of the desirable action. The desirable action cost to the principal is simply the cost to the agent, $f\left(a_{i}-N_{a_{i}}\right)$. In contrast, the undesirable action imposes costs on the principal from two sources. First, there is the cost that arises from putting the agents into a situation where they are induced to take undesirable actions, $f\left(u_{i}+N_{u_{i}}\right)$. This cost of undertaking $u_{i}$ is borne directly by agent $i$ and indirectly by the principal, who pays agent $i$ 's wages. Second, there is the direct cost of the undesirable action to the principal, $k_{i} u_{i}$.

If both $a_{i}$ and $u_{i}$ are strictly positive for $i \in \mathcal{I}$, which we assume for the remainder of the paper, then the principal's problem can be exploited to characterize the minimum cost of implementing $\left\{a_{i}\right\}_{i \in \mathcal{I}}$ as a function of those actions, as well as the exogenous variables. In particular, recall from Lemma 2 that $a_{i}-N_{a_{i}}=u_{i}+N_{u_{i}}$ for each agent. It follows that the cost function (11) can be written

$$
\frac{\int_{\mathcal{I}} v+2 f\left(a_{i}-N_{a_{i}}\right)+k_{i}\left(a_{i}-N_{a_{i}}-N_{u_{i}}\right) d i}{\int_{\mathcal{I}} d i},
$$

where $N_{a_{i}}=\left(1-\alpha_{i}\right) A_{i}+\alpha_{i} S_{a}, N_{u_{i}}=\left(1-\mu_{i}\right) U_{i}+\mu_{i} S_{u}, S_{a}=\int_{\mathcal{I}} a_{i} d i / \int_{\mathcal{I}} d i$, and

$$
S_{u}=\frac{\int_{\mathcal{I}}\left(1-\alpha_{i}\right)\left(A_{i}-S_{a}\right)+\left(1-\mu_{i}\right) U_{i} d i}{\int_{\mathcal{I}}\left(1-\mu_{i}\right) d i} .
$$

Consider the relation between the set of desirable actions induced and each of the social norms. When financial incentives are increased, there is an interdependent set of effects on action choices and norms. First, the level of desirable action chosen by the agents increases. Second, the social norm for the desirable action increases, which follows directly from the definition of the social norm for the desirable action. Third, it follows from (13) that the social norm for the undesirable action decreases when the social norm for the desirable action increases. This 
relation arises because more undesirable action is induced by the increased financial incentives. The increase in undesirable action, in turn, erodes the social norm that discourages the undesirable action. Hence, motivating the agents to increase the level of the desirable action necessarily leads them to supply more of the undesirable action and also erodes the social norm thwarting the undesirable action.

\section{Organizational Boundaries}

Economic entities often include individuals who specialize in different productive activities (e.g., auditing and consulting, or sales and service). If the returns to desirable actions across productive actions differ, it is preferable to induce higher levels of desirable action from some individuals than from others. Section III established that the cost of implementing a level of desirable action from an individual is a function of the social norm faced by that individual which is, in turn, a function of the behavior of others in the same organization. By managing the boundaries of each agent's organization, then, it is possible to alter the implementation cost of a given set of desirable actions. ${ }^{8}$ In this section, a simple example highlights factors that may induce organizations to combine or subdivide so as to alter social norms and thereby lower implementation costs.

Assume a set of identical agents indexed on $[0,1]$ are to be employed. All agents have the same behavioral traits: $A_{i}=A, \alpha_{i}=\alpha, U_{i}=U$, and $\mu_{i}=\mu$ for $i \in[0,1]$. A high level of the desirable action, $a_{h}$, is required for a proportion $\delta \in(0,1)$ of the agents, and a lower level, $a_{l}<a_{h}$, is required from the remaining agents. The former opportunity might be thought of as a new line of business with growth prospects and the latter as a mature line of business. Throughout our analysis, we assume that these actions are independent of organizational structure. Hence, our analysis is concerned with identifying the least costly structure for a given set of desirable actions.

To demonstrate how organizational boundaries matter, consider two possible cases. In the first case, all agents work in the same organization, so the social norm is computed over all agents. In the second case, there are two organizations, each with its own social norm. One organization implements $a_{l}$ from each agent and employs proportion $1-\delta$ of the agents. The other organization implements $a_{h}$ from each agent and employs the remaining agents.

Two sources of cost must be considered when comparing the costs associated with single and separate organizations: the costs of compensating the agents, and the costs of undesirable actions incurred by the principal. We assume that these latter costs increase linearly in the per capita level of the undesirable action. Parameters $k_{h}$ and $k_{l}$ denote the unit costs to the principal of the undesirable actions by the agents producing $a_{h}$ and $a_{l}$, respectively. We assume these costs, too, are independent of organizational structure. Given the specific additional assumptions in this section, the single-organization implementation cost is

$$
\begin{aligned}
C_{1}= & v+\delta\left[f\left(a_{h}-N_{\hat{a}}\right)+f\left(\hat{u}_{h}+N_{\hat{u}}\right)+k_{h} \hat{u}_{h}\right] \\
& +(1-\delta)\left[f\left(a_{l}-N_{\hat{a}}\right)+f\left(\hat{u}_{l}+N_{\hat{u}}\right)+k_{l} \hat{u}_{l}\right],
\end{aligned}
$$

where $\hat{u}_{j}$ denotes the undesirable action of the agents who implement $a_{j}$ when there is a single organization, and $N_{\hat{a}}=(1-\alpha) A+\alpha\left[\delta a_{h}+(1-\delta) a_{l}\right]$ and $N_{\hat{u}}=(1-\mu) U-\mu\left[\delta \hat{u}_{h}+(1-\delta) \hat{u}_{l}\right]$

\footnotetext{
${ }^{8}$ One approach to creating organization boundaries is to create separate firms. A more subtle approach that may introduce boundaries within a firm involves putting physical or social distance between employees engaging in different tasks.
} 
are, respectively, the norms associated with the desirable and undesirable actions in the single organization. The two-organization implementation cost is

$$
\begin{aligned}
C_{2}=v+ & \delta\left[f\left(a_{h}-N_{a_{h}}\right)+f\left(u_{h}+N_{u_{h}}\right)+k_{h} u_{h}\right] \\
& +(1-\delta)\left[f\left(a_{l}-N_{a_{l}}\right)+f\left(u_{l}+N_{u_{l}}\right)+k_{l} u_{l}\right],
\end{aligned}
$$

where $u_{j}$ denotes the undesirable action of the agents who implement $a_{j}$ when there are two organizations, and $N_{a_{h}}=(1-\alpha) A+\alpha a_{h}, N_{u_{h}}=(1-\mu) U-\mu u_{h}, N_{a_{l}}=(1-\alpha) A+\alpha a_{l}$, and $N_{u_{l}}=(1-\mu) U-\mu u_{l}$ are the norms on desirable and undesirable actions associated with the implementing $a_{h}$ and $a_{l}$, respectively, in separate organizations.

\section{A. Cost Comparison}

Compare first the compensation costs across the one- and two-organization structures, given in (14) and (15), which exclude the terms involving $k_{h}$ or $k_{l}$. With separate organizations, neither agent type influences the other type, so the desirable action social norm and the agent's desirable action choice coincide: $S_{a_{h}}=a_{h}$ and $S_{a_{l}}=a_{l} \cdot{ }^{9}$ In contrast, with a single organization, there is a common desirable action social norm, $S_{\hat{a}}$, which is between the levels of action implemented for the two agent types: $a_{l}<S_{\hat{a}}=\delta a_{h}+(1-\delta) a_{l}<a_{h}$. Therefore, the norm faced by an agent in a single organization $N_{\hat{a}}$ satisfies $N_{a_{l}}<N_{\hat{a}}<N_{a_{h}}$. Relative to the case with separate organizations, it follows that agents who implement $a_{h}$ in a single organization incur higher costs of the desirable action because the desirable action social norm is intermediate (rather than high), while agents who implement $a_{l}$ incur a lower cost because the norm is intermediate (rather than low).

Assessing the difference in costs incurred by the agents for the undesirable action is more complicated because the undesirable action social norm and the undesirable action choices themselves differ across the organization structures. ${ }^{10}$ Lemma 2 guarantees that $a_{i}-N_{a_{i}}=u_{i}+$ $N_{u_{i}}$, which simplifies matters because agents' costs for the undesirable action are identical to their costs for the desirable action. This observation, coupled with the discussion of costs for desirable actions above, implies that agents implementing $a_{h}$ incur lower costs for undesirable actions in separate organizations, while the agents implementing $a_{l}$ incur higher costs for undesirable actions in separate organizations.

Relative to the case with separate organizations, the convexity of the cost function, $f$, implies that the higher costs incurred by the agents implementing $a_{h}$ in a single organization exceed the lower costs faced by the agents implementing $a_{l}$. Consequently, separate organizations minimize the total compensation costs.

Having established that separate organizations minimize the compensation costs, consider next the principal's total costs, which also include the direct cost from the agents' undesirable actions. The organization structure that minimizes the direct costs is the one that minimizes the undesirable action for the type of agent that generates the greatest cost per unit of undesirable action. Hence, which structure is best depends on the agents' relative sensitivities to the social norms, $\alpha$ and $\mu$, as well as the cost parameters $k_{h}$ and $k_{l}$.

When the agents are more sensitive to social norms for the undesirable action, $\mu>\alpha$, behavior is primarily managed through the social norm for undesirable action. If the agents implementing $a_{l}$ impose the higher cost per unit of undesirable action, $k_{l}>k_{h}$, the direct cost of undesirable action is minimized by having separate organizations because the social norm thwarting the undesirable action faced by the agents implementing $a_{l}$ is higher with separate organizations.

\footnotetext{
${ }^{9}$ Similarly, for the undesirable action: $S_{u_{h}}=-u_{h}$ and $S_{u_{l}}=-u_{l}$.

${ }^{10}$ In general, $u_{h} \neq \hat{u}_{h}$ and $u_{l} \neq \hat{u}_{l}$. It can be shown that $N_{u_{h}}<N_{\hat{u}}<N_{u_{l}}$ for $\mu>0$.
} 
Among agents implementing $a_{l}$ in a separate organization, the social norm for the undesirable action is separate from, and so undiminished by, the negative influence of the agents implementing $a_{h}$, who naturally take more undesirable action. If the cost of undesirable action is greater for the agents implementing $a_{h}$, then a single organization minimizes costs because the undesirable action social norm faced by the agents implementing $a_{h}$ is higher due to the positive influence of agents implementing $a_{l}$.

When the agents are more sensitive to the social norm for the desirable action, $\alpha>\mu$, similar reasoning applies, although the outcome of that reasoning is different. In the case where the agents implementing $a_{l}$ generate a higher cost per unit of undesirable action, a single organization minimizes the cost of undesirable action because of the positive influence that the agents implementing $a_{h}$ exert on the desirable action social norm faced by the agents implementing $a_{l}$. When the agents implementing $a_{h}$ generate a higher cost per unit of undesirable action, separate organizations minimize the costs of undesirable actions because the agents implementing $a_{l}$ do not have a negative influence on the social norm for the desirable action of the agents implementing $a_{h}$.

Proposition 1 summarizes the combined effects of the two sources of cost.

PROPOSITION 1: Assume that the agents are identical and that the principal seeks to induce some proportion $\delta$ of these agents to implement a high level of the desirable action, $a_{h}$, and the remainder to implement a low level of the desirable action, $a_{l}<a_{h}$. The cost of inducing these actions are lower if the agents assigned to produce $a_{h}$ are in a separate organization from the agents assigned to produce $a_{l}$, if and only if: (i) the agents are more sensitive to the social norm for the desirable action, that is $\alpha>\mu$, and $k_{h}-k_{l}$ is sufficiently large; (ii) the agents are more sensitive to the social norm for the undesirable action, that is, $\mu>\alpha$, and $k_{h}-k_{l}$ is sufficiently small; or (iii) the agents are equally sensitive to each social norm, $\alpha=\mu>0$.

\section{B. Discussion}

The case where the social norm for the undesirable action is more important to the determination of action choices offers a perspective on public accounting firms that provide both consulting and auditing services. In such a professional services firm, the revenues secured by a partner are a primary performance measure for that partner. A consequence of employing revenue as a performance measure, however, is that each partner has incentives to set aside his own professional judgment and appease client management to secure revenues from that client. Furthermore, like the undesirable action in our model, appeasement is controlled to some extent by a social norm for adhering to high professional standards.

Prominent commentators allege that there is a costly erosion of norms for auditors when a public accounting firm provides both consulting and auditing services. For example, Arthur R. Wyatt (2003, 17), formerly a senior partner and Managing Director-Accounting Principles at Arthur Andersen (a once prominent but now defunct public accounting firm), emphasizes this erosion in his account of the firm's collapse: "The infusion of new personnel, some at relatively high levels, who lacked a background that placed prominence on accounting professionalism gradually gained increasing influence in accounting firms. ... Staff personnel within the firms were easily able to observe the attributes of those who were the rapidly rising stars and undertook efforts to emulate these attributes. ... [K] eeping the client happy and doing what was necessary to retain the client achieved a prominence that did not exist prior to the advent of the successful consulting arms with the firms. The core values of the professional firm were undermined by primarily commercial interests." ${ }^{11}$

\footnotetext{
${ }^{11}$ See also Levitt (2000).
} 
We can frame Wyatt's allegation in the context of the model by contrasting the costs of an auditor and a consultant appeasing a client. Appeasement in an audit engagement can result in the significant reputation and legal costs associated with an audit failure. Appeasement in a consulting engagement can result in the costs of a botched consulting assignment, which are likely to be much lower than those of an audit failure (i.e., the $k$ for auditing exceeds the $k$ for consulting). Proposition 1 suggests that, if the incentives provided to consultants are more powerful than those provided to auditors, splitting the firm into two organizations, audit and consulting, may be valuable because doing so preserves a high social norm among auditors.

The benefit of dividing an organization to preserve norms must be weighed against the synergistic gains from combining in a single organization agents assigned to different tasks. For example, synergies arise when auditors sell their firm's consulting services to their audit clients. If the synergies are so large that splitting up the organization is inefficient, then organizations might adapt in other ways to preserve social norms. For instance, in firms combining auditing and consulting services, the incentives for consultants may be weaker than those in a consulting-only firm, because weaker incentives (i.e., lower $b_{i}$ 's) imply that lower levels of the desirable and undesirable actions are chosen by consultants. In turn, this leads to a higher social norm for the undesirable action in the firm, which induces a lower level of the undesirable action from the auditors. As another alternative, when norms are low, it becomes worthwhile to install additional control systems. For instance, firms that combine consulting and auditing may implement more extensive reviews of audit files by partners charged with quality control.

A related set of considerations follows from relaxing the assumption that the direct costs to the principal of the undesirable actions are independent of the organizational structure. In particular, one might suspect that misconduct in one branch of a multiservice firm would adversely affect the entire brand and not just the branch where it occurred, suggesting that $k_{h}$ and $k_{l}$ might both be larger in a single organization. If so, incentives would be lower in larger organizations, ceteris paribus.

\section{Implementation Costs and Behavioral Traits}

Research in social psychology suggests that individuals differ in how much they are influenced by a social, as opposed to a personal, norm. ${ }^{12}$ If individuals differ in their sensitivities to social norms, two questions naturally arise. First, what type of individuals will an organization prefer-those who are more sensitive to a social norm or those who are less sensitive? Second, will an organization naturally attract the individuals with the preferred trait?

\section{A. Which Behavioral Trait Is Preferred?}

To assess which behavioral trait is preferred, assume the behavioral parameters are the same for every agent: $\alpha_{i}=\alpha, \mu_{i}=\mu, A_{i}=A$, and $U_{i}=U$ for all $i \in \mathcal{I}$. Further, assume all agents are assigned to the same organization and induced to undertake the same level of desirable action. Given the assumption of interior choices for both actions, it follows from (12) and (13) that the per capita cost of inducing action $a$ in the organization is

$$
C(a)=v+2 f((a-A)(1+\alpha))+k\left[\frac{(a-A)(1-\alpha)}{1-\mu}-U\right] .
$$

\footnotetext{
${ }^{12}$ See, for example, Kohlberg (1984) and Denis Arnold and Lawrence A. Ponemon (1991).
} 
PROPOSITION 2: Assume identical agents who make a desirable action choice and an undesirable action choice. If $a$ is low, then the cost of implementing a for all agents in the organization is increasing (decreasing) as the agents become more sensitive to the social norms for the desirable (undesirable) action: for $a<A, d C(a) / d \alpha>0$ and $d C(a) / d \mu<0$. If $a$ is high, then the converse is true: for $a>A, d C(a) / d \alpha<0$ and $d C(a) / d \mu>0$.

The intuition underlying Proposition 2 stems directly from the observation that the principal is better off when the agents face higher norms (i.e., higher $N_{a}$ and $N_{u}$ ). Given the relation between norms and implementation costs, establishing the relation between the sensitivity to social norms and implementation costs directly follows from the relation between the sensitivity to the social norms and the norms faced by each agent. Consider, first, the agents' sensitivity to the norm for the desirable action. When $a>A$, the social norm for the desirable action, $S_{a}=a$, is greater than the personal norm for the desirable action, $A$. Hence, the norm for the desirable action is increasing in the sensitivity to the social norm for the desirable action, which implies that the implementation costs are reduced when agents are more sensitive to the social norm for the desirable action. The converse is true when $a<A$.

Consider, next, the agents' sensitivities to the norm for the undesirable action. When $a>A$, the social norm for the undesirable action, $S_{u}=-u$, is less than the personal norm for the undesirable action, $U$. The social norm is less than the personal norm because the higher level of desirable action requires incentives that are so strong that agents are induced to undertake a level of undesirable action in excess of their personal norm for the undesirable action. Because the social norm is less than the personal norm, the norm for the undesirable action is decreasing in the sensitivity to the underlying social norm. As a consequence, implementation costs are increasing in the sensitivity to the social norm for the undesirable action. The opposite is true when $a<A$.

\section{B. Will Agents Self-Select?}

Having identified the agent traits the principal values, the second question raised earlier can be addressed: when agent characteristics are not observable, will the principal be able to attract the agents with the desired traits to the organization? To develop some insight, we consider a simple setting, which we call the example setting. Assume half the agents are more sensitive to one of the two social norms and the other half are less sensitive to that social norm. The agents are otherwise identical. The principal forms an organization that will hire only half the agents and induce action $a$ from each of them. We consider two possible cases, one where agents differ only in their sensitivity to the desirable action social norm and the other where they differ only in their sensitivity to the undesirable action social norm. For each case, we assess whether the principal can attract only the agents with the preferred sensitivity to the social norm.

Consider first the case where agents differ only in their sensitivity to the social norm for the desirable action. Proposition 2 implies that the principal strictly prefers to hire agents with a low sensitivity to the social norm for the desirable action if $a$ is less than the common personal norm for the desirable action $A$. Proposition 2 further implies that the principal strictly prefers to hire agents with the high sensitivity to the social norm for the desirable action when $a>A$. Observation 1 implies that the principal attracts exactly those agents when type is not observable by offering the same contract as is optimal to offer when type is observable.

OBSERVATION 1: When agents must self-select in the example setting and the agents differ only in their sensitivity to the social norm for the desirable action, the optimal contract offered to the desired agent types in the setting where types are observable is accepted only by the desired agent types in the setting where types are unobservable. 
Self-selection works in the principal's interest in this case because the principal's and agents' interests are aligned. The principal wants to attract agents who can deliver desirable action at the lowest cost, and the agent types naturally attracted to the organization are those who can increase the performance measure at the lowest cost. When agents differ only in their sensitivity to the social norm for the desirable action, the agents who deliver desirable action at the lowest cost also deliver the performance measure at the lowest cost, so the most suitable agents are naturally attracted to the organization. Hence, the principal attracts the agents who are best suited to the task without incurring adverse selection costs.

Consider, next, the case where the agents differ only in their sensitivity to the social norm for the undesirable action. In this case, Proposition 2 implies that the principal strictly prefers to hire agents with a high sensitivity to the social norm when $a<A$ and the agents with a low sensitivity when $a>A$. Observation 2 suggests that adverse selection problems are insurmountable when there are unobserved differences in the sensitivity to social norms for undesirable actions.

OBSERVATION 2: When agents must self-select in the example setting and the agents differ only in their sensitivity to the social norm for the undesirable action, there does not exist a contract that attracts only the desired agent type and induces them to take the level of desirable action a for any $a \neq A$.

The self-selection problem arises in this case because the interests of the principal and agents are not aligned. Recall that the principal wants to attract agents who can deliver desirable action at the lowest cost, and agents naturally attracted to the organization are those who can increase the performance measure at the lowest cost. When agents differ only in their sensitivity to the social norm for the undesirable action, the principal wants those agents who have the highest norm for the undesirable action, which are those who are most sensitive to the social norm for the undesirable action when $a<A$ and those who are least sensitive to that social norm when $a>$ $A$. In contrast, the agents who can generate the performance measure at the lowest cost are those with the lowest norm for the undesirable action. Hence, the principal's and agents' interests are not aligned and the principal always attracts the least suitable agents.

At a general level, these observations lead to predictions that particular organizations are likely to attract agents with particular sensitivities to social norms, which in turn leads to differences in individual norms of behavior across (as opposed to within) organizations. If a profession such as public accountancy or law is viewed as an organization, this implication is consistent with the evidence in Ponemon and David R. L. Gabhart (1994) that individuals' sensitivities to norms vary systematically across professions. Furthermore, the existence of different norms at different firms is consistent with survey findings in William J. Bruns and Kenneth A. Merchant, Jr. (1990), who document a wide range of attitudes toward various types of undesirable earnings management activities across firms. In addition to providing a model that is consistent with this evidence, our analysis yields the additional prediction that the power of financial incentives should be related to the average sensitivity to social norms for individuals within an organization, as well as the norms that emerge. For example, individuals at firms with high-powered incentives are predicted to be more sensitive to norms of behavior regarding earnings management and to exhibit lower norms of behavior (i.e., a higher tolerance) for earnings management.

\section{Personal Norms}

We have focused our analysis on differences in agents' sensitivities to social norms because they have been measured and studied by social psychologists. Nonetheless, we also point out that issues of self-selection are likely to arise when agents have different personal norms (i.e., 
$A_{i} \neq A_{j}$ and $U_{i} \neq U_{j}$ for some agents $i$ and $j$ ). The principal always prefers agents with higher personal norms pertaining to both the desirable and undesirable actions because higher norms promote the desirable action and thwart the undesirable action. Paralleling the discussion above, when agents differ only in their personal norms for the desirable action in the example setting, it can be shown that there is no costly adverse selection problem when type is not observable. In contrast, when agents differ only in their personal norms for the undesirable action in the example setting, there is a costly adverse selection problem when type is not observable. In particular, the principal attracts agents with a low personal norm whenever agents with a high personal norm are attracted. Hence, self-selection again works in favor of the principal when there are differences only in the norms for the desirable action, but works against the principal when there are differences in the norms for the undesirable actions.

\section{Summary and Conclusion}

We consider some implications of endogenous social norms for organizational design by analyzing a model in which a principal employs a continuum of agents who each choose two actions, a desirable action that is beneficial to the principal and an undesirable action that is costly to the principal. Each agent chooses a mix of these actions because both favorably affect the performance measure used for contracting with that agent. The critical aspect of social norms in our model is that an agent's behavior is influenced by the behavior of others in his organization. In particular, the cost of an action to an agent is reduced as other agents in the same organization engage in more of that action. Although it would be interesting to examine a setting in which some agents have a disproportionate influence on norms, for example, highly visible leaders such as politicians or CEOs who set the "tone at the top" of an organization, our analysis focuses on the role of social norms in settings where no individual agent has a measurable impact on the social norm, but the social norm is nevertheless endogenous and influences the action choice of every agent.

Our analysis suggests that social norms influence three aspects of organization design: the financial incentives provided to members of an organization, the boundaries of an organization, and the types of agents in an organization. Social norms create multiplier effects associated with changes in the power of financial incentives. Specifically, the effect of an increase in the power of financial incentives on the desirable action is multiplied by the presence of a social norm for the desirable action and reduced by the presence of a social norm for the undesirable action. It follows that an increase in financial incentives may lead to larger or smaller changes than would arise in the absence of norm considerations. Therefore, norms should influence the power of financial incentives within an organization.

We demonstrate in a simple setting how it can be optimal to split an organization into two separate organizations in order to eliminate the externalities the agents with high-powered incentives create for those agents with low-powered incentives, and vice versa. These considerations emerge in ongoing debates such as whether accounting firms should provide both auditing and consulting services. More generally, our analysis suggests that an organization's boundaries should be chosen in light of the norms those boundaries engender.

A last aspect of organization design that is likely to be influenced by the presence of social norms is the types of agents that an organization attracts. Social psychology research suggests that individuals differ in their sensitivities to social norms. Given such differences in individual behavioral traits, two questions naturally arise: What behavioral traits does an organization prefer? And, can an organization attract the individuals with those traits? When agents differ in their sensitivities to social norms for desirable actions, agents who are more sensitive to those norms are preferred when high-powered incentives are employed (i.e., when the level of desirable 
action is high) because these agents incur the lowest cost for taking the desirable action. In contrast, agents who are less sensitive to the norm are preferred when low-powered incentives are employed. Furthermore, agents with the desired trait are matched naturally to an organization because the principal seeks agents with the lowest personal cost for the desirable action, and the agents with the lowest cost of the desirable action are attracted naturally to the organization because they can generate performance at the lowest personal cost.

When agents differ in their sensitivities to social norms for undesirable actions, agents who are less sensitive to those norms are preferred when high-powered incentives are employed (i.e., when the level of desirable action is high) because these agents incur the highest cost for taking the costly undesirable action. In contrast, agents who are more sensitive to the norm are preferred when low-powered incentives are employed. Unlike the case where agents differ in their sensitivities to social norms for the desirable action, agents with the preferred trait do not self-select into the organization because the principal seeks the agents with the highest personal cost for the undesirable action, while the agents with the lowest personal cost for the undesirable action can generate performance at the lowest personal cost.

Because the norms affecting undesirable actions and desirable actions can have different implications, determining the social norm to which agents are most sensitive is key to assessing how norms influence organizational design choices. We conjecture that norms for undesirable actions are likely to be more important in settings where other barriers to performance measure manipulation are weak or absent. For example, within the context of a firm, we expect that norms relating to undesirable actions are relatively more important when the firm's other monitoring mechanisms, such as an active independent board, are weak; when the firm engages in transactions where the accounting is complex and requires significant subjective estimates; and when the firm has significant leverage over its suppliers and customers, which makes it easier to collude with them to manipulate financial reports.

We have restricted our attention to the implications of social norms for organization design. Social norm considerations, however, are relevant to other issues of economic interest such as understanding how technological changes undermine the legal system and codes of ethical behavior (i.e., standards of professional conduct and student honor codes that social norms support). For example, the development of the Internet and the digitization of copyrighted materials have facilitated the undesirable acts of copyright violation via music file sharing and plagiarism, not only by making such acts physically easier, but also by eroding the social norms that discouraged such acts. Accordingly, exploring the roles played by social norms should provide useful insights in other areas of economic research.

\section{REFERENCES}

Arnold, Denis, and Lawrence A. Ponemon. 1991. "Internal Auditors' Perceptions of Whistle-blowing and the Influence of Moral Reasoning: An Experiment." Auditing: A Journal of Theory and Practice, 10(2): $1-15$.

Bénabou, Roland, and Jean Tirole. 2003. "Intrinsic and Extrinsic Motivation." Review of Economic Studies, 70(3): 489-520.

Blomquist, N. Soren. 1993. "Interdependent Behavior and the Effect of Taxes." Journal of Public Economics, 51(2): 211-18.

Bolton, Gary E., and Axel Ockenfels. 2000. "ERC: A Theory of Equity, Reciprocity, and Competition." American Economic Review, 90(1): 166-93.

Bruns, William J., and Kenneth A. Merchant, Jr. 1990. “The Dangerous Morality of Managing Earnings." Management Accounting, 72(2): 22-25.

Charness, Gary, and Matthew Rabin. 2002. "Understanding Social Preferences with Simple Tests." Quarterly Journal of Economics, 117(3): 817-69. 
Davis Jon S., Gary Hecht, and Jon D. Perkins. 2003. "Social Behaviors, Enforcement, and Tax Compliance Dynamics." Accounting Review, 78(1): 39-69.

Dye, Ronald A. 1988. "Earnings Management in an Overlapping Generations Model." Journal of Accounting Research, 26(2): 195-235.

Erickson, Merle, Michelle Hanlon, and Edward L. Maydew. 2004. "How Much Will Firms Pay for Earnings That Do Not Exist? Evidence of Taxes Paid on Allegedly Fraudulent Earnings." The Accounting Review, 79(2): 387-408.

Fehr, Ernst, and Armin Falk. 2002. "Psychological Foundations of Incentives." European Economic Review, 46(4-5): 687-724.

Fields, Thomas D., Thomas Z. Lys, and Linda Vincent. 2001. "Empirical Research on Accounting Choice." Journal of Accounting and Economics, 31(1-3): 255-307.

Fischer, Paul E., and Robert E. Verrecchia. 2000. "Reporting Bias." Accounting Review, 75(2): $229-45$.

Fisman, Raymond, and Edward Miguel. 2006. "Cultures of Corruption: Evidence from Diplomatic Parking Tickets.” http://www2.gsb.columbia.edu/faculty/rfisman/parking 20july06 RF.pdf.

Gneezy, Uri, and Aldo Rustichini. 2000a. “A Fine Is a Price.” Journal of Legal Studies, 29(1): 1-17.

-Gneezy, Uri, and Aldo Rustichini. 2000b. "Pay Enough or Don't Pay at All." Quarterly Journal of Economics, 115(3): 791-810.

Hirshleifer, David. 1993. "Managerial Reputation and Corporate Investment Decisions.” Financial Management, 22(2): 145-60.

-Holmström, Bengt, and Paul Milgrom. 1991. "Multitask Principal-Agent Analyses: Incentive Contracts, Asset Ownership, and Job Design.” Journal of Law, Economics, and Organization, 7(3): 24-52.

Huck, Steffen, Dorothea Kübler, and Jörgen W. Weibull. 2006. "Social Norms and Economic Incentives." http://else.econ.ucl.ac.uk/papers/uploaded/62.pdf.

Kim, E. Han, Adair Morse, and Luigi Zingales. 2006. "Are Elite Universities Losing Their Competitive Edge?" http://ssrn.com/abstract=900920.

Kohlberg, Lawrence. 1984. Essays on Moral Development Vol. 2, The Psychology of Moral Development. San Francisco: Harper \& Row.

Levitt, Arthur. 1998. “The 'Numbers Game.” Paper presented at the New York University School of Law, Center for Law and Business, New York.

Levitt, Arthur. 2000. "Renewing the Covenant With Investors.” Paper presented at the New York University School of Law, Center for Law and Business, New York.

Lindbeck, Assar, Sten Nyberg, and Jörgen Weibull. 1999. "Social Norms, the Welfare State, and Voting." Quarterly Journal of Economics, 114(1): 1-35.

Oyer, Paul. 1998. "Fiscal Year Ends and Nonlinear Incentive Contracts: The Effect on Business Seasonality." Quarterly Journal of Economics, 113(1): 149-85.

Ponemon, Lawrence A., and David R. L. Gabhart. 1994. "Ethical Reasoning Research in the Accounting and Auditing Professions." In Moral Development in the Professions, ed. James R. Rest and Darcia Narvaez, 101-19. Mahwah, NJ: Erlbaum.

-Prendergast, Canice. 1999. “The Provision of Incentives in Firms.” Journal of Economic Literature, 37(1): 7-63.

Rotter, Julian B. 1966. "Generalized Expectancies for Internal Versus External Control of Reinforcement." Psychological Monographs, 80(1): 1-28.

Slemrod, Joel. 2004. "The Economics of Corporate Tax Selfishness." National Bureau of Economics Working Paper 10858.

Sliwka, Dirk. 2007. "Trust as a Signal of a Social Norm and the Hidden Costs of Incentive Schemes." American Economic Review, 97(3): 999-1012.

-Stein, Jeremy C. 1989. "Efficient Capital Markets, Inefficient Firms: A Model of Myopic Corporate Behavior.” Quarterly Journal of Economics, 104(4): 655-69.

Wyatt, Arthur R. 2003. “Accounting Professionalism-They Just Don’t Get It!” Paper presented at the annual meeting of the American Accounting Association, Honolulu. 


\section{This article has been cited by:}

1. Milan Zafirovski. 2016. Rational Choice Theory at the Origin? Forms and Social Factors of "Irrational Choice”. Social Epistemology 30:5-6, 728-763. [CrossRef]

2. Andrea Szczesny, Christian Ernst. 2016. The Role of Performance Reporting System Characteristics for the Coordination of High-Cost Areas in Hospitals. European Accounting Review 25:4, 635-660. [CrossRef]

3. Gary Bolton, Peter Werner. 2016. The influence of potential on wages and effort. Experimental Economics 19:3, 535-561. [CrossRef]

4. Pedro Forquesato. 2016. Social norms of work ethic and incentives in organizations. Journal of Economic Bebavior \& Organization 128, 231-250. [CrossRef]

5. Joan Luft. 2016. Cooperation and competition among employees: Experimental evidence on the role of management control systems. Management Accounting Research 31, 75-85. [CrossRef]

6. Erin L. Krupka, Stephen Leider, Ming Jiang. 2016. A Meeting of the Minds: Informal Agreements and Social Norms. Management Science . [CrossRef]

7. Jeong-Bon Kim, Leye Li, Louise Yi Lu, Yangxin Yu. 2016. Financial statement comparability and expected crash risk. Journal of Accounting and Economics 61:2-3, 294-312. [CrossRef]

8. PATRICK SCHNEIDER, GAUTAM BOSE. 2016. Organizational Cultures of Corruption. Journal of Public Economic Theory n/a-n/a. [CrossRef]

9. Anastasia Danilov, Dirk Sliwka. 2016. Can Contracts Signal Social Norms? Experimental Evidence. Management Science . [CrossRef]

10. Christiane Bradler, Robert Dur, Susanne Neckermann, Arjan Non. 2016. Employee Recognition and Performance: A Field Experiment. Management Science . [CrossRef]

11. Joan Luft. 2016. Management accounting in the laboratory and in social context: Four contrasts, 1975-2014. Accounting, Organizations and Society 49, 9-20. [CrossRef]

12. Eddy Cardinaels, Yuping Jia. 2016. How Audits Moderate the Effects of Incentives and Peer Behavior on Misreporting. European Accounting Review 25:1, 183-204. [CrossRef]

13. Jeremy Bertomeu, Iván Marinovic. 2016. A Theory of Hard and Soft Information. The Accounting Review 91:1, 1-20. [CrossRef]

14. Suren BasovSocial Norms and Optimal Contracts 119-146. [CrossRef]

15. Janne O. Y. Chung, Sylvia H. Hsu. 2015. The Effect of Cognitive Moral Development on Honesty in Managerial Reporting. Journal of Business Ethics . [CrossRef]

16. Yingchao Zhang, Oliver Fabel, Christian Thomann. 2015. Pay inequity effects on back-office employees' job performances: the case of a large insurance firm. Central European Journal of Operations Research 23:2, 421-439. [CrossRef]

17. Thomas Aronsson, David Granlund. 2015. Gender norms, work hours, and corrective taxation. Journal of Behavioral and Experimental Economics 56, 33-39. [CrossRef]

18. Botao Qin, Jason F. Shogren. 2015. Social norms, regulation, and environmental risk. Economics Letters 129, 22-24. [CrossRef]

19. Simi Kedia, Kevin Koh, Shivaram Rajgopal. 2015. Evidence on Contagion in Earnings Management. The Accounting Review . [CrossRef]

20. Illoong Kwon, Daesung Jun. 2015. Information disclosure and peer effects in the use of antibiotics. Journal of Health Economics 42, 1. [CrossRef]

21. 2015. Journal of Health Economics 42. . [CrossRef] 
22. Milan Zafirovski. 2014. Rational Choice Requiem: The Decline of an Economic Paradigm and its Implications for Sociology. The American Sociologist 45:4, 432-452. [CrossRef]

23. Stanley Baiman. 2014. Some Ideas for Further Research in Managerial Accounting. Journal of Management Accounting Research 26:2, 119-121. [CrossRef]

24. Bryan K. Church, R. Lynn Hannan, Xi Jason Kuang. 2014. Information Acquisition and Opportunistic Behavior in Managerial Reporting. Contemporary Accounting Research 31:2, 398-419. [CrossRef]

25. Caspar Siegert. 2014. Bonuses and managerial misbehaviour. European Economic Review 68, 93-105. [CrossRef]

26. Eddy Cardinaels, Naomi Soderstrom. 2013. Managing in a Complex World: Accounting and Governance Choices in Hospitals. European Accounting Review 22:4, 647-684. [CrossRef]

27. Lava Prakash Yadav, Stephen O'Neill. 2013. Is there agreement between beneficiaries on who should bear the costs of conserving farm landscapes?. Tourism Management 39, 62-70. [CrossRef]

28. VICTOR S. MAAS, MARCEL VAN RINSUM. 2013. How Control System Design Influences Performance Misreporting. Journal of Accounting Research n/a-n/a. [CrossRef]

29. Bruce I. Davidson, Douglas E. Stevens. 2013. Can a Code of Ethics Improve Manager Behavior and Investor Confidence? An Experimental Study. The Accounting Review 88:1, 51-74. [CrossRef]

30. Jeremy D. Douthit, Linwood W. Kearney, Douglas E. Stevens. 2012. Can Agent Cheap Talk Mitigate Agency Problems in the Presence of a Noisy Performance Measure? An Experimental Test in a Singleand Multi-Period Setting. Journal of Management Accounting Research 24:1, 135-158. [CrossRef]

31. Joaquín Gómez-Miñambres. 2012. Motivation through goal setting. Journal of Economic Psychology 33:6, 1223-1239. [CrossRef]

32. Katarina Nordblom, Jovan Žamac. 2012. Endogenous Norm Formation Over the Life Cycle - The Case of Tax Morale. Economic Analysis and Policy 42:2, 153-170. [CrossRef]

33. Scott D. Dyreng, William J. Mayew, Christopher D. Williams. 2012. Religious Social Norms and Corporate Financial Reporting. Journal of Business Finance \& Accounting 39:7-8, 845-875. [CrossRef]

34. Christian Ernst, Andrea Szczesny, Naomi Soderstrom, Frank Siegmund, Alexander Schleppers. 2012. Success of Commonly Used Operating Room Management Tools in Reducing Tardiness of First Case of the Day Starts. Anesthesia \& Analgesia 115:3, 671-677. [CrossRef]

35. Mirko S. Heinle, Christian Hofmann, Alexis H. Kunz. 2012. Identity, Incentives, and the Value of Information. The Accounting Review 87:4, 1309-1334. [CrossRef]

36. Steffen Huck, Dorothea Kübler, Jörgen Weibull. 2012. Social norms and economic incentives in firms. Journal of Economic Behavior \& Organization 83:2, 173-185. [CrossRef]

37. MARGARET H. CHRIST, SCOTT A. EMETT, SCOTT L. SUMMERS, DAVID A. WOOD. 2012. The Effects of Preventive and Detective Controls on Employee Performance and Motivation*. Contemporary Accounting Research 29:2, 432-452. [CrossRef]

38. CLARA XIAOLING CHEN, TATIANA SANDINO. 2012. Can Wages Buy Honesty?

The Relationship between Relative Wages and Employee Theft. Journal of Accounting Research nono. [CrossRef]

39. GUY KAPLANSKI, HAIM LEVY. 2012. EXECUTIVE SHORT-TERM INCENTIVE, RISKTAKING AND LEVERAGE-NEUTRAL INCENTIVE SCHEME. Annals of Financial Economics 07:01, 1250003. [CrossRef]

40. Daniel G. Arce. 2012. Principals' preferences for agents with social preferences. Journal of Economic Bebavior \& Organization. [CrossRef] 
41. Stephen V. Burks, Erin L. Krupka. 2012. A Multimethod Approach to Identifying Norms and Normative Expectations Within a Corporate Hierarchy: Evidence from the Financial Services Industry. Management Science 58:1, 203-217. [CrossRef]

42. Timo Goeschl, Grischa Perino. 2011. Instrument Choice and Motivation: Evidence from a Climate Change Experiment. Environmental and Resource Economics . [CrossRef]

43. WILLIAM B. TAYLER, ROBERT J. BLOOMFIELD. 2011. Norms, Conformity, and Controls. Journal of Accounting Research no-no. [CrossRef]

44. James B. Rebitzer, Lowell J. TaylorExtrinsic Rewards and Intrinsic Motives: Standard and Behavioral Approaches to Agency and Labor Markets 701-772. [CrossRef]

45. Dirk Wolfson. 2010. Situational Contracting as a Mode of Governance. Public Management Review 12:6, 857-872. [CrossRef] 